\title{
Uveal melanoma diagnosis and current treatment options (Review)
}

\author{
DANIEL CONSTANTIN BRANISTEANU ${ }^{1 *}$, CAMELIA MARGARETA BOGDANICI ${ }^{1}$, \\ DACIANA ELENA BRANISTEANU ${ }^{2}$, MINELA AIDA MARANDUCA ${ }^{3 *}$, MIHAIL ZEMBA $^{4 *}$, \\ FLORIAN BALTA $^{4}$, CATALINA IOANA BRANISTEANU ${ }^{5}$ and ANDREEA DANA MORARU ${ }^{1}$

\begin{abstract}
Departments of ${ }^{1}$ Ophthalmology, ${ }^{2}$ Dermatology and ${ }^{3}$ Physiology, 'Grigore T. Popa' University of Medicine and Pharmacy, 700115 Iasi; ${ }^{4}$ Department of Ophthalmology, 'Carol Davila' University of Medicine and Pharmacy, 050474 Bucharest;

5، Grigore T. Popa' University of Medicine and Pharmacy, 700115 Iasi, Romania
\end{abstract}

Received July 26, 2021; Accepted August 25, 2021

DOI: $10.3892 / \mathrm{etm} .2021 .10863$

\begin{abstract}
Uveal melanoma is a rare condition accounting for only $5 \%$ of all primary melanoma cases. Still, it is the most frequently diagnosed primary intraocular malignant tumor in adults. Almost $90 \%$ of the tumors involve the choroid and only a small percentage affects the ciliary body or the iris. There is a consistent difference in incidence between different regions with individuals of northern European descent having a significantly higher risk as compared to Hispanics, Asians, and Blacks. Among the many risk factors, mutations in the $\mathrm{G}$ protein subunit alpha $\mathrm{Q}(G N A Q)$ or $\mathrm{G}$ protein subunit alpha 11 (GNA11) genes and different receptors are highly suggestive. While iris melanoma can easily be noticed by the patient itself or diagnosed at a routine slit-lamp evaluation, a consistent percentage of posterior uveal tumors are incidentally diagnosed at funduscopic evaluation as they can evolve silently for years, especially if located in the periphery. Uveal melanoma classifications rely on the tumor size (thickness and basal diameter) and also on intraocular and extraocular extension. The differential diagnosis with pseudomelanomas is carried out according to the tumor aspect and position. Iris melanoma has a better prognosis and a lower mortality rate as compared to choroidal melanoma that has a much higher rate of metastasis (50\% of the patients) and a subsequent limited life expectancy
\end{abstract}

Correspondence to: Professor Camelia Margareta Bogdanici, Department of Ophthalmology, 'Grigore T. Popa' University of Medicine and Pharmacy, 16 Universitatii Street, 700115 Iasi, Romania

E-mail: camelia.bogdanici@umfiasi.ro

Professor Daciana Elena Branisteanu, Department of Dermatology, 'Grigore T. Popa' University of Medicine and Pharmacy, 16 Universitatii Street, 700115 Iasi, Romania

E-mail: daciana.branisteanu@umfiasi.ro

*Contributed equally

Key words: uveal melanoma, diagnosis, treatment, metastatic disease, review from 6 to 12 months. While conservative therapeutic options for the primary tumor, relying on different surgical excision techniques and/or irradiation therapies, offer good local tumor control, the treatment options for metastatic disease, although numerous, are still inadequate in preventing a fatal outcome.

\section{Contents}

1. Introduction

2. Diagnosis of uveal melanoma

3. Differential diagnosis and prognosis

4. Treatment options in uveal melanoma and metastatic disease

5. Conclusions

\section{Introduction}

Uveal melanomas are uncommon but potentially lifethreatening ocular conditions. They develop from melanocytes located in the highly pigmented uveal tract, the main oxygen, and nutriment provider of the retina. Anterior uveal melanomas originate in the iris while posterior uveal melanomas emerge from the choroid or the ciliary body. Among these tumors, choroidal melanoma is the most frequently diagnosed tumor (almost $90 \%$ of all uveal melanomas) followed by ciliary body melanoma ( $6 \%$ of the cases) and iris melanoma ( $4 \%$ of the cases) $(1,2)$. Although uveal melanomas account for only $5 \%$ of all primary melanoma cases (90\% located in the skin), they represent the most frequently diagnosed primary intraocular malignant tumor in adults.

While the incidence of cutaneous melanomas have continuously increased, the incidence of uveal melanomas has remained constant in the last decades across all continents. However, there are consistent differences in incidence between different areas worldwide (3). In the US, the incidence varies from 5.1 to 6 cases per million population per year, being highest in the southern latitudes (3). In Europe, the incidence of uveal melanomas is much higher (up to 8 cases per million population per year) in Caucacians of northern European descent (Scandinavia and Baltic States) and significantly lower in Italy (3.3 cases per million population per year), and Spain (1.9 cases 
per million population per year) (4). Hispanics and Asians have a lower incidence while Black individuals have the lowest one. The relative risk of uveal melanoma has been estimated to be $1 / 1.2 / 5 / 19$ in Blacks/Asians/Hispanics/Non-Hispanics, respectively (5).

There is no consistent sex-related difference; still, in epidemiological studies, the age-adjusted incidence has revealed that men have an increased predominance (5.8 per million in males as compared to 4.4 per million in females) (3). Uveal melanomas are uncommon in children. While the mean age for diagnosis has increased from 55 years of age to 62 years of age in Caucasians, in Asian countries uveal melanoma seems to appear at a younger age (6). Therefore, the mean age for diagnosis varies from 45 years of age (in the Chinese population) to 55 years of age (in the Japanese population).

To date, there are several risk factors identified in uveal melanoma development. Host susceptibility factors such as light-colored eyes, fair skin color, dysplastic nevus syndrome, ocular melanocytosis, and xeroderma pigmentosum have been confirmed as predisposing factors $(7,8)$. In particular, a preexisting iris or choroidal nevus is of major concern as they can evolve into melanoma. The continuous nevus growth, together with the appearance of ectropion uveae and/or spontaneous hyphema (in the case of iris nevus) and subretinal fluid and orange pigmentation (in the case of choroidal nevus) highly suggests a transformation into melanoma (9). Excessive exposure to natural and artificial ultraviolet light and also to blue light have been suggested as risk factors (10). Patients with BRCA1-associated protein $1(B A P l)$ mutation are considered to have a higher risk for developing uveal melanomas at a younger age (11). Most uveal melanomas have mutations in the $\mathrm{G}$ protein subunit alpha $\mathrm{Q}(G N A Q)$ or $\mathrm{G}$ protein subunit alpha 11 (GNA11) genes (90\%) (12) and in the phospholipase $\mathrm{C} \beta 4$ (PLCB4) and the $\mathrm{G}$-protein coupled receptor cysteinyl leukotriene receptor 2 (CYSLTR2) $(13,14)$. In metastatic disease, there is a loss of chromosome 1p that leads to higher mortality when accompanied by the concurrent loss of chromosome 3 (15).

For this review, the authors performed an extensive literature search in the Medline electronic database, using the PubMed interface. The keyword combinations used were 'uveal melanoma', 'iris melanoma', 'ciliary body melanoma', 'choroidal melanoma' and, in turn, each of the following: 'diagnosis', 'treatment', 'metastatic'. We included articles in English, published from January 1, 1990 to February 28, 2021. After filters were applied (case report, classical article, guideline, journal article, meta-analysis, observational study, review, systematic review) a consistent number of 3,012 references resulted. Among these, 93 references were cited in this review.

\section{Diagnosis of uveal melanoma}

Iris melanoma is incidentally diagnosed at slit-lamp evaluation, usually much earlier (10 to 20 years) than other uveal melanomas. Sometimes, the patient solely notices the iris color changes (heterochromia). In most cases, the tumor is circumscribed, located inferiorly, and induces pupillary distortion (corectopia). Ectropion iridis, hyphema, secondary glaucoma, cataract, and extraocular extension are the most frequent complications. The intraocular pressure rise is the consequence of trabecular meshwork invasion or direct angle compression. The diagnosis of diffuse iris melanoma is more challenging and is often delayed due to the infiltrative pattern. Ring iris melanoma is a rare entity with angle location often simulating unilateral pigmentary glaucoma (16). The T1-T4 classification with further subgroups of iris melanoma, according to the American Joint Committee on Cancer Classification (AJCC), is based on tumor size (clock hours), tumor extension (ocular and extraocular), and complications (glaucoma) (17). While ultrasound biomicroscopy (UBM) and anterior segment optical coherence tomography (AS-OCT) are helpful tools in evaluating small anterior tumors, the B-scan ultrasonography can better evaluate larger tumors with posterior extension. Fine needle aspiration biopsy (FNAB) confirms the diagnosis (18).

The diagnosis of posterior uveal melanoma is usually performed by an experienced clinician during a routine slit-lamp biomicroscopy and/or indirect ophthalmoscopy under dilated pupil, as many tumors (especially ciliary body tumors) can silently grow for years and are totally asymptomatic (up to $40 \%$ of the cases). Most frequent complaints include floaters and photopsia. While tumors located in the periphery can reach consistent dimensions until visual field loss is noted, in locations closer to the macula and to the optic disc, the cystoid macular edema or secondary retinal detachment induces prompt visual loss. The funduscopic evaluation typically reveals a pigmented dome-shaped nodular mass, well-circumscribed, located under the retinal pigment epithelium. The degree of pigmentation can largely vary. In partially pigmented (30\% of the cases) and amelanotic tumors $(15 \%$ of the cases), the abnormalities of overlying retinal pigment epithelium and also the tumor vascularization can be easily observed. An accompanying massive exudative retinal detachment can hide the diagnosis. A mushroom-shaped aspect highly suggests that the Bruch membrane has been surpassed and is noted in $20 \%$ of the cases. Rarely, large tumors induce vitreous hemorrhage. Tumors located anteriorly show dilated overlying episcleral vessels ('sentinel vessels'), secondary glaucoma due to the anterior iris-lens diaphragm displacement or tumor extension into the angle, and cataract. Severe ocular pain due to posterior ciliary nerve involvement, transscleral tumor growth under the conjunctival, and proptosis due to orbital extension have also been reported (19).

According to the Collaborative Ocular Melanoma Study (COMS), choroidal melanoma is classified as small (largest basal diameter $\leq 16 \mathrm{~mm}$, apical height between 1.5 and $2.4 \mathrm{~mm}$ ), medium-sized (largest basal diameter $\leq 16 \mathrm{~mm}$, apical height between 2.5 and $10 \mathrm{~mm}$ ), and large (largest basal diameter $\leq 16 \mathrm{~mm}$, apical height $\geq 10 \mathrm{~mm}$ ) (20). The American Joint Committee on Cancer (AJCC) has updated the staging system according to size criteria (T1-T4), ciliary body involvement, and episcleral extension (21).

There is a consistent improvement in uveal melanoma diagnosis accuracy in the last decades, from around $20 \%$ to more than $99 \%$, as indicated by the COMS (20). The $10 \mathrm{MHz}$ B-scan ultrasonography is an essential evaluation tool in ocular oncology, easily revealing tumors with a thickness of more than $1.5 \mathrm{~mm}$. It is particularly useful in opaque intraocular media. On B-scans, uveal melanomas have different shapes (collar-stud or mushroom appearance), have a low to moderate internal reflectivity, present a choroidal excavation, 
and can be accompanied by a secondary retinal detachment. This technique is essential for measuring tumor dimensions, evaluating the extent, planning the treatment, and follow-up. The $40 \mathrm{MHz}$ anterior UBM can visualize anterior uveal melanomas and differentiate them from those originating in the ciliary body. On A-scan there is a highly reflective anterior border followed by decreased amplitude as the tumor mass is acoustically hollow (positive kappa angle), and a significant final echo. Transillumination, which is particularly helpful in finding tumor borders, has a limited precision in partially pigmented and amelanotic tumors (19).

Fluorescein angiography (FA) and indocyanine green angiography (ICG) offer no pathognomonic signs in uveal melanomas. They have a limited contribution in differentiating choroidal nevi from small tumors but they can reveal, in larger tumors, a patchy fluorescent pattern (in FA) and the internal tumor vascularization known as 'double circulation pattern' (mainly in ICG). Fundus autofluorescence due to lipofuscin pigmentation is more intense than the autofluorescence of drusen usually seen in choroidal nevi. Orbital computed tomography (CT) and magnetic resonance imaging (MRI) with contrast are less sensitive diagnostic tools but help detect the extrascleral extension and in differentiating choroidal melanoma (which is enhanced by contrast) from choroidal detachment (no contrast enhancement) or choroidal osteoma (calcium detection). The Color Doppler ultrasound can differentiate the tumor from choroidal nevi due to the presence of a typical pulsatile blood flow at the tumor base. While regular spectral-domain OCT has limitations in accessing the tumor internal structure, the newer enhanced depth imaging spectral domain OCT can see deeper into the choroid and reveal the tumor, the thinned choriocapillaris, the accompanying retinal fluid, retinal changes, and retinal deposits (lipofuscin). An incisional biopsy is an invasive diagnostic tool involving the risk of complications and cancerous cell spreading and is currently indicated in uncertain cases only, such as amelanotic tumors (22).

On the contrary, fine-needle aspiration biopsy (FNAB) may soon become a standard procedure in conservatively treated melanomas as it provides the samples mandatory for genetic analysis with direct implications in prognosis and metastasis rates (23). Thus, according to gene expression profiling (GEP), ocular melanomas have been subdivided into 2 types. Class 1 tumors (further subdivided into class $1 \mathrm{a}$ and $1 \mathrm{~b}$ ), representing almost $50 \%$ of the cases, have a low and intermediate metastatic risk at 5 years ( 2 and $21 \%$, respectively), while class 2 tumors have a significantly higher risk $(72 \%)(23,24)$. The histological evaluation of the enucleated eye reveals 3 types of tumor cells: spindle A, spindle B, and epithelioid. The epithelioid has frequent mitotic figures, morphologic variations and is highly anaplastic. Thus, epithelioid cell melanoma and mixed cell melanoma are considered to have a significantly poorer prognosis as compared to spindle cell melanomas and necrotic melanomas (25).

\section{Differential diagnosis and prognosis}

The differential diagnosis of uveal melanoma is difficult. For circumscribed iris melanoma, it may include iris nevi, ocular melanocytosis, different iris nodules (sarcoidosis, juvenile xanthogranuloma), iris cysts, essential iris atrophy, iris foreign body, other iris tumors (leiomyoma), and metastasis. Diffuse iris melanoma should be mainly differentiated from diffuse iris nevi, ocular siderosis, pigmentary glaucoma, and congenital heterochromia. The most frequent posterior pseudomelanomas are represented by choroidal nevi, peripheral exudative hemorrhagic chorioretinopathy (PEHCR), congenital hypertrophy of the retinal pigment epithelium, hemorrhagic detachment of the retina or pigment epithelium (PED), choroidal detachment, circumscribed choroidal hemangioma, choroidal osteoma, and metastatic tumors (26).

Overall, iris melanoma has a better prognosis and a lower mortality rate as it develops metastases in only 2 to $7 \%$ of the cases, higher (10\%) if there is mixed cellularity or ciliary body involvement. Choroidal melanoma has a much higher rate of metastasis (in almost $50 \%$ of the cases), mainly hematogenously, involving the liver (90\%), the lungs, the brain, the kidneys, and the bones (27). The subsequent life expectancy is limited from 6 to 12 months (28). For many years, the tumor size, epithelioid type, ciliary body or optic nerve involvement, and extrascleral extension were considered as the main indicators for metastasis and mortality. Currently, the specific genetic profile (chromosome 3 deletion, chromosome $8 \mathrm{q}$ gain, BAP1 loss, chromosome 1p and 9q loss, Class 2 GEP) seems to be a better indicator for metastatic disease (29). Liver enzyme levels and chest X-rays should be routinely performed at the time of diagnosis to rule out the most frequent concomitant liver and/or lung metastasis (30).

\section{Treatment options in uveal melanoma and metastatic disease}

The main goals of ocular melanoma treatment are to destroy the tumor, prevent recurrence and metastasis, and conserve vision. While the treatment of primary uveal melanoma has constantly improved over time and different irradiation procedures have successfully replaced enucleation in selected cases, the therapeutic options for metastatic disease are still disappointing $(29,30)$. The therapeutic attitude in primary uveal melanoma must take into account the tumor size, location and extension, the visual function, the status of the fellow eye, the age and health status of the patient, and last but not least the presence of metastasis $(18,19)$.

Observation. Usually, small uveal lesions are closely monitored clinically and with sequential photography. While UBM is a helpful adjunct in monitoring iris lesions, B-scan ultrasonography is mandatory to detect any signs of growth of posterior lesions.

In the literature, iris nevi have a transforming rate estimated at $5 \%$ in 5 years and $11 \%$ in 20 years (31). On a larger series, the transformation rate was $2 \%$ at a mean follow-up of 5.6 years and $8 \%$ by 15 years (32). A systematical evaluation of predictive factors according to the mnemonic $\mathrm{ABCDEF}$ (A, age younger than 40 years; B, blood (hyphema); $\mathrm{C}$, clock hour inferiorly (location); D, diffuse flat configuration; E, ectropion uveae, and $\mathrm{F}$, feathery margins) was proposed to simplify the early detection of iris nevus growth into melanoma (32).

Choroidal nevi evolution must also be carefully monitored. Usually, choroidal nevi are a chronic condition easily 
recognizable by the accompanying drusen and pigment epithelium atrophy on the surface and by the nonpigmented surrounding halo. They are detected in about $6 \%$ of the Caucasian population and have an annual conversion rate into melanoma that increases with age, estimated between 1 in 5,000 and 1 in 8,800 cases $(33,34)$. Nevertheless, the appearance of visual symptoms, subretinal fluid, increasing thickness over $2 \mathrm{~mm}$, orange pigmentation, absence of drusen and surrounding halo, ultrasound hollowness, and margin touching the optic disc are considered indicators for tumor conversion (9). Like in iris melanoma, the mnemonic TFSOM UHHD ('To Find Small Ocular Melanoma Using Helpful Hints'), derived from 'Thickness, Fluid, Symptoms, Orange pigment, Margin, Ultrasonographic Hollowness, Halo absence, and Drusen absence' was created by Shields et al to help practitioners to better evaluate the ocular melanoma risk factors $(9,35)$. A careful evaluation of these features is of particular importance as the chance for tumor growth at 5 years is around $3 \%$ when no risk factors are encountered and over $50 \%$ when two or more factors are noted (35).

Prospective cohort studies suggest that early treatment is better than observation, in some patients, for preventing death from metastatic disease $(36,37)$. In the particular case of elderly patients with active tumors, but with consistent comorbidities restricting therapeutic options or very low life expectancy, observation is a feasible choice (19).

\section{Surgical treatments}

Enucleation. This radical surgical technique, once the gold standard in the treatment of intraocular tumors, is still indicated in large uveal melanomas ( $>18 \mathrm{~mm}$ in basal diameter and $>12$ mm in thickness), in cases with total visual loss due to severe complications and in tumors refractory or recurrent to conservative treatments $(16,19,22,30)$. Eyes with advanced orbital tumor extension are currently treated more conservatively avoiding orbital exenteration by combining enucleation with local radiation therapy (38). The Zimmerman-McLean-Foster hypothesis that enucleation accelerates mortality has been ruled out (39). Nevertheless, enucleation must be carefully performed as any excessive manipulation or injury to the affected eye during surgery carries the risk for tumor cell spreading into the bloodstream and orbital tissue, as suggested by the occurrence of orbital recurrences after enucleation. Performing external radiation before enucleation does not change the 10-year survival rate in large choroidal melanoma as compared to enucleation alone (40). The superiority of enucleation over conservative iodine-125 brachytherapy in reducing the risk of metastasis in medium-sized tumors has not been confirmed by the Collaborative Ocular Melanoma Study (COMS) in up to 12 years of follow-up (41).

Surgical excisions. Small iris melanoma is often successfully managed by sector iridectomy, especially if the tumor induces secondary glaucoma or interferes with the vision. Iridocyclectomy is preferred in rapidly growing iris tumors involving the angle $(19,42)$. The surgical excision of choroidal melanomas has limited indications on small tumors only (19). Sclerouvectomy (transscleral resection) is a full-thickness excision including the sclera, the tumor, the choroid, and the retina. Usually, the scleral excision is around $3 \mathrm{~mm}$ larger than the melanoma. While banked sclera is mandatory for reconstruction, adjacent transscleral cryotherapy is necessary for retinal stability. Lamellar sclerouvectomy is less invasive to the retina than the previous technique (due to the partial-thickness scleral flap) but it carries a much higher risk for tumor reoccurrence (43). The most frequent complications of surgical excision are retinal detachment, vitreous hemorrhage, incomplete tumor removal, and cataract. Tumor endoresection during pars-plana vitrectomy is technically feasible but requires vast experience as the tumor margins are not always clearly visible. Although there is a major concern about the intraocular and extraocular tumor spread during surgery, a study found a lower rate of metastatic spread during endoresection $(3.7 \%)$ as compared to the iodine 125 brachytherapy group (20.4\%) (44). Nevertheless, the addition of local radiotherapy reduces the reoccurrence rate $(45,46)$.

\section{Irradiation therapies}

Brachytherapy. Conservative treatment using a radioactive plaque temporarily sutured on the sclera adjacent to the tumor is one of the oldest (since the 1980's), most effective, and widespread methods for controlling medium-sized posterior uveal melanomas (47). It is also effective in iris melanoma treatment, but it has a significantly higher rate of cataract formation and eyelid scarring. The plaques have different sizes and shapes and must exceed the largest basal diameter of the tumor by $2 \mathrm{~mm}$ (48). The intraoperative usage of transillumination is mandatory to adequately temporarily attach to the sclera the plaque that will be removed after 3-7 days. Different isotopes with good tissue penetration are used to radioactively charge the plaques. Among them, ruthenium 106 is most frequently used in Europe while in the US iodine 125 is preferred. The usage of cobalt 60, iridium 192, palladium 103 and strontium 90 is less frequent (49). The time and the amount of energy delivered are calculated according to the tumor size. Thus, efficient, customized irradiation is performed at both the tumor base and apex with minimal adjacent tissue involvement. Brachytherapy is highly effective in tumor destruction so most of the treated melanomas show a consistent regression or even total flattening $(47,50)$. While the tumor resistance rate widely varies between different centers, the local recurrence rate after iodine 125 or ruthenium 106 brachytherapy (in a diffuse manner or starting from the initial tumor margins) is estimated at $9.6 \%$ of cases and indicates the need for enucleation (51). Second double-dose brachytherapy has shown long-term efficacy in further decreasing or stabilizing the tumor size thus reducing the need for enucleation (52). A Swedish long-term patient survival study after plaque ruthenium 106 brachytherapy performed between 1980 and 1999, revealed excellent relative survival rates $(97 \%$ at 1 year, $74 \%$ at 5 years, $64 \%$ at 10 years, $64 \%$ at 15 years, $62 \%$ at 20 years, $70 \%$ at 25 years, $83 \%$ at 30 years, $114 \%$ at 35 years and $200 \%$ at 40 years) and that $82 \%$ of uveal melanoma-related deaths occurred in the first decade after treatment (53). A retrospective evaluation of small choroidal melanomas treated with iodine 125 between 2004 and 2017 also showed that, after 3 years of follow-up, the survival rate was $97 \%$ with no metastatic events and that $69 \%$ of the patients retained visual acuity of at least 20/50 (54). Unfortunately, brachytherapy carries the risk of local complications such as cataract formation, 
scleral necrosis, neovascular glaucoma, and dry eye (55). Radiation retinopathy is dependent on radiation dose and can occur in around $30 \%$ of the treated patients within 2 years of treatment (56). Radiation maculopathy and in particular radiation-induced macular edema can be efficiently controlled with intravitreal anti-vascular endothelial growth factor treatment or intravitreal dexamethasone implants (57). Radiation optic neuropathy is responsible for irreversible, sudden onset, visual loss within years after treatment of a tumor mainly located near the optic disc, most probably due to irreversible local vascular damage (58).

Proton beam radiotherapy. Developed in the early 1990s, charged-particle radiation is a newer conservative treatment, using protons or helium ions as charged particles to more precisely and much more safely deliver the desired amount of energy in different tumor parts. This method is a frequent conservative alternative to brachytherapy or enucleation for the treatment of unresectable or diffuse iris melanoma and in medium-sized or larger posterior melanomas if a charged-particle accelerator is available. The treatment is usually fractionated and is preceded, in the case of posterior uveal melanomas, by the initial scleral suture of tantalium rings that serve as radiopaque tumor reference markers. During the irradiation sessions, the head and eye must be carefully positioned. Although the efficacy seems to be similar to brachytherapy (59), there are major advantages due to more homogenous and focused treatment and less damage on the surrounding tissue (60). Still, radiation-associated complications can occur in time in almost $50 \%$ of the cases (61). Similar to brachytherapy, most of the tumors stop growing or regress after treatment. Also, the enucleation and the recurrence rates after treatment are comparable. The survival rate after charged-particle irradiation is comparable to that after enucleation $(62,63)$.

Photon radiotherapy. (A recent meta-analysis of gamma knife radiosurgery as a primary treatment option in more than 1,000 uveal melanoma cases in the last 5 decades has shown that gamma knife radiosurgery is efficient in controlling the tumor in $96 \%$ of the cases with a 5-year survival rate of $76 \%$. Still, further comparative randomized studies are needed to evaluate the position of this technique in the current therapeutic armamentarium (64).

\section{Laser therapies}

Direct laser photocoagulation. Direct laser photocoagulation of the uveal melanoma was the first conservative method introduced by Dr Meyer-Schwickerath in the early 50's (65). Today, this technique, with limited indication on small tumors only located at a distance from the fovea, is abandoned in many centers due to the modesttumor control and the increased rate of recurrence. Moreover, direct laser photocoagulation is associated with an increased risk of tumor extension through the Bruch's membrane, choroidal neovascularization, macular edema, retinal tractions and detachment, and vitreous hemorrhage (66).

Transpupillary thermotherapy (TTT). TTT uses a near-infrared diode laser. The local rise in temperature slightly over $45^{\circ} \mathrm{C}$ offers better results than direct photocoagulation in the control of small melanomas and a lower tumor reoccurrence rate, especially when used in conjunction with brachytherapy (48). In a retrospective evaluation of primary TTT in choroidal melanoma, the tumor reoccurrence rate in a 2001-2012 group was $11 \%$ at 5 years and $15 \%$ at 10 years, significantly lower than in the previous group treated between 1995 and 2000 (67). Complications after TTT are noted in 44\% of the cases and include retinal vascular occlusions, cystoid macular edema, epiretinal membranes, vitreous hemorrhage, optic disc atrophy, retinal traction and detachment (68).

Photodynamic therapy (PDT). PDT using verteporfin as a photosensitizer has been FDA approved in ophthalmology since the 2000's for the selective treatment of choroidal neovascularization secondary to various conditions due to minimal surrounding destruction. Primary PDT was found to be followed by complete tumor regression in $67 \%$ of small amelanotic choroidal melanomas at 5-year follow-up with no significant side effects on macular or optic nerve function (69). A recent meta-analysis of published studies found an overall $80 \%$ response rate to treatment, especially in small amelanotic tumors (70). While these results suggest that PDT is an effective primary treatment for small choroidal melanoma, especially in cases without pigmentation, further long-term studies are required for validation.

Treatments for metastatic disease. Although metastatic disease is detected in less than $1 \%$ of the patients with uveal melanoma at the time of initial diagnosis (71), a significant percentage of these patients will develop in time metastatic disease (31\% of cases within 5 years, $45 \%$ within 15 years, and almost $50 \%$ within 25 years) (72). The dramatic decline in survival rate from $70 \%$ at 5 years for primary disease to only $8 \%$ at 2 years after metastatic disease as reported (73) confirms the need for an urgent treatment regimen and appropriate psycho-oncology support in such cases (74).

The usage of systemic chemotherapy has offered poor results suggesting that uveal melanoma is resistant to current chemotherapies. Conventional drugs (dacarbazine, temozolomide, and fotemustine), and many of the modern agents (paclitaxel, docosahexaenoic acid, and liposomal vincristine) have offered discouraging results, in monotherapy and also in combination. The most encouraging data have been noted with the combination of treosulfan and gemcitabine that showed a median survival of 14 months and an annual survival rate of $80 \%$ (75). Still, due to the frequent hematological, neurological, and pulmonary adverse effects that consistently lower the quality of life in these patients, systemic chemotherapy has not been routinely implemented for the treatment of metastatic disease (76).

Chemoimmunotherapy has also limited efficacy in uveal melanoma. The immune privilege of the eye may explain why promising preliminary results of recombinant interferon $\alpha-2 b$ associated with the BOLD regimen (bleomycin, vincristine, lomustine, and dacarbazine) were not confirmed (77).

While immunotherapy alone using different agents (ipilimumab, pembrolizumab, or nivolumab) has shown limited results, the combination therapy (of ipilimumab with one of the previously mentioned agents) has offered 
encouraging results with an overall survival rate of around 19 months (78-82). The side effects were found to vary from easily manageable skin reactions and pseudo-flu symptoms to more serious autoimmune colitis and thyroid and pituitary hormonal alterations. A consistent number of phase I and II clinical trials are currently underway to evaluate the efficacy and safety of novel immune-based therapies (such as cell-based and peptide vaccines, adoptive transfer of autologous TILs or CAR-T cells directed against human epidermal growth factor receptor 2) or different therapeutic combinations (pembrolizumab and entinostat, ipilimumab and melphalan PHP, ipilimumab and laparoscopic radiofrequency ablation) $(50,83)$.

Molecular-targeted therapy seemed to be a suitable approach for uveal melanoma due to the distinctive genetic profile, with mutations in the GNAQ and GNAll genes stimulating cell proliferation (83). Unfortunately, several mitogen-activated protein kinase (MAPK) pathway inhibitors (used alone or in combination with chemotherapy) and also heat shock protein 90 inhibitors have failed to exhibit significant efficacy in clinical trials $(50,84)$.

In regards to hepatic metastasis, liver-directed therapies, including intra-arterial chemotherapy with fotemustine, transarterial liver chemoembolization, and isolated hepatic perfusion have shown, besides their significant theoretical advantages, encouraging results in different studies (85-89). Different surgical laparoscopic excisions (alone or combined with radiofrequency ablation), liver radioembolization (using yttrium-90 microspheres), and liver thermotherapy have also shown promising results and are under evaluation (90-93).

\section{Conclusions}

The prognosis, survival rate, and quality of life in primary uveal melanoma tumors have significantly improved since the introduction of conservative irradiation therapies and surgical excisions. On the contrary, despite the consistent knowledge that has been acquired in the last decades regarding tumor genetics and pathogenesis (especially the biological and immunological mechanisms leading to tumor growth and spreading), there is to date no efficient therapeutic algorithm in controlling the metastatic disease responsible for a quick fatal outcome in almost $50 \%$ of the patients. Hopefully, the multiple clinical studies ongoing on this topic will soon confirm the encouraging preliminary results leading to more efficient and safer therapeutic protocols that will consistently increase the survival rate of these patients.

\section{Acknowledgements}

Not applicable.

\section{Funding}

No funding was received.

\section{Availability of data and materials}

All information provided in this review is documented by relevant references.

\section{Authors' contributions}

DCB and ADM contributed to the study design, participated in the entire review process, and prepared the manuscript. CIB, $\mathrm{FB}, \mathrm{MAM}$, and MZ performed the bibliography research, and data analysis.. DEB and CMB contributed to the critical revision. All authors read and approved the final version of the manuscript.

\section{Ethics approval and consent to participate}

Not applicable.

\section{Patient consent for publication}

Not applicable.

\section{Competing interests}

All the authors declare that they have no competing interests.

\section{References}

1. Shields CL, Furuta M, Thangappan A, Nagori S, Mashayekhi A, Lally DR, Kelly CC, Rudich DS, Nagori AV, Wakade OA, et al: Metastasis of uveal melanoma millimeter-by-millimeter in 8033 consecutive eyes. Arch Ophthalmol 127: 989-998, 2009.

2. Maranduca MA, Branisteanu D, Serban DN, Branisteanu DC, Stoleriu G, Manolache N and Serban IL: Synthesis and physiological implications of melanic pigments. Oncol Lett 17: 4183-4187, 2019.

3. Singh AD, Turell ME and Topham AK: Uveal melanoma: Trends in incidence, treatment, and survival. Ophthalmology 118: 1881-1885, 2011.

4. Virgili G, Gatta G, Ciccolallo L, Capocaccia R, Biggeri A, Crocetti E, Lutz JM and Paci E; EUROCARE Working Group: Incidence of uveal melanoma in Europe. Ophthalmology 114: 2309-2315, 2007.

5. Hu DN, Yu GP, McCormick SA, Schneider S and Finger PT: Population-based incidence of uveal melanoma in various races and ethnic groups. Am J Ophthalmol 140: 612-617, 2005.

6. Tan LLY, Hong J, Goh WL, Chang EW, Yang VS, Poon E, Somasundaram N, Farid M, Chan AS and Chan JY: Clinical features and survival outcomes of ocular melanoma in a multi-ethnic Asian cohort. Sci Rep 10: 16367, 2020.

7. Hammer H, Oláh J and Tóth-Molnár E: Dysplastic nevi are a risk factor for uveal melanoma. Eur J Ophthalmol 6: 472-474, 1996.

8. Shields CL, Kaliki S, Livesey M, Walker B, Garoon R, Bucci M, Feinstein E, Pesch A, Gonzalez C, Lally SE, et al: Association of ocular and oculodermal melanocytosis with the rate of uveal melanoma metastasis: Analysis of 7872 consecutive eyes. JAMA Ophthalmol 131: 993-1003, 2013.

9. Shields CL, Furuta M, Berman EL, Zahler JD, Hoberman DM, Dinh DH, Mashayekhi A and Shields JA: Choroidal nevus transformation into melanoma: Analysis of 2514 consecutive cases. Arch Ophthalmol 127: 981-987, 2009.

10. Shah CP, Weis E, Lajous M, Shields JA and Shields CL: Intermittent and chronic ultraviolet light exposure and uveal melanoma: A meta-analysis. Ophthalmology 112: 1599-1607, 2005.

11. Harbour JW, Onken MD, Roberson ED, Duan S, Cao L, Worley LA, Council ML, Matatall KA, Helms C and Bowcock AM: Frequent mutation of BAP1 in metastasizing uveal melanomas. Science 330: 1410-1413, 2010.

12. Van Raamsdonk CD, Bezrookove V, Green G, Bauer J, Gaugler L, O'Brien JM, Simpson EM, Barsh GS and Bastian BC: Frequent somatic mutations of GNAQ in uveal melanoma and blue naevi. Nature 457: 599-602, 2009.

13. Johansson P, Aoude LG, Wadt K, Glasson WJ, Warrier SK, Hewitt AW, Kiilgaard JF, Heegaard S, Isaacs T, Franchina M, et al: Deep sequencing of uveal melanoma identifies a recurrent mutation in PLCB4. Oncotarget 7: 4624-4631, 2016. 
14. Moore AR, Ceraudo E, Sher JJ, Guan Y, Shoushtari AN, Chang MT, Zhang JQ, Walczak EG, Kazmi MA, Taylor BS, et al: Recurrent activating mutations of G-protein-coupled receptor CYSLTR2 in uveal melanoma. Nat Genet 48: 675-680, 2016.

15. Kilic E, Naus NC, van Gils W, Klaver CC, van Til ME, Verbiest MM, Stijnen T, Mooy CM, Paridaens D, Beverloo HB, et al: Concurrent loss of chromosome arm 1p and chromosome 3 predicts a decreased disease-free survival in uveal melanoma patients. Invest Ophthalmol Vis Sci 46: 2253-2257, 2005.

16. Conway RM, Chua WC, Qureshi C and Billson FA: Primary iris melanoma: Diagnostic features and outcome of conservative surgical treatment. Br J Ophthalmol 85: 848-854, 2001.

17. Kivelä T, Simpson RE and Grossniklaus HE: Uveal melanoma. In: AJCC Cancer Staging Manual. 8th edition. Amin B, Edge SB and Greene FL (eds). Springer, New York, NY, pp805-817, 2017.

18. Russo A, Avitabile T, Reibaldi M, Bonfiglio V, Pignatelli F, Fallico M, Caltabiano R, Broggi G, Russo D, Varricchio S, et al: Iris Melanoma: Management and prognosis. Appl Sci 10: 8766, 2020.

19. Kaliki S and Shields C: Uveal melanoma: Relatively rare but deadly cancer. Eye (Lond) 31: 241-257, 2017.

20. No authors listed: Accuracy of diagnosis of choroidal melanomas in the collaborative ocular melanoma study. COMS report no. 1 Arch Ophthalmol 108: 1268-1273, 1990.

21. Finger PT; 7th Edition, AJCC-UICC Ophthalmic Oncology Task Force: The 7th edition AJCC staging system for eye cancer: An international language for ophthalmic oncology. Arch Pathol Lab Med 133: 1197-1198, 2009

22. Singh P and Singh A: Choroidal melanoma. Oman J Ophthalmol 5 : 3-9, 2012

23. Onken MD, Worley LA, Char DH, Augsburger JJ, Correa ZM, Nudleman E, Aaberg TM Jr, Altaweel MM, Bardenstein DS, Finger PT, et al: Collaborative ocular oncology group report number 1: Prospective validation of a multi-gene prognostic assay in uveal melanoma. Ophthalmology 119: 1596-1603, 2012.

24. Onken MD, Worley LA, Tuscan MD and Harbour JW: An accurate, clinically feasible multi-gene expression assay for predicting metastasis in uveal melanoma. J Mol Diagn 12: 461-468, 2010.

25. No authors listed: Histopathologic characteristics of uveal melanomas in eyes enucleated from the collaborative ocular melanoma study. COMS report no. 6. Am J Ophthalmol 125 745-766, 1998

26. Shields CL, Manalac J, Das C, Ferguson K and Shields JA Choroidal melanoma: Clinical features, classification, and top 10 pseudomelanomas. Curr Opin Ophthalmol 25: 177-185, 2014.

27. Diener-West M, Reynolds SM, Agugliaro DJ, Caldwell R, Cumming K, Earle JD, Hawkins BS, Hayman JA, Jaiyesimi I, Jampol LM, et al: Development of metastatic disease after enrollment in the COMS trials for treatment of choroidal melanoma: Collaborative ocular melanoma study group report No. 26. Arch Ophthalmol 123: 1639-1643, 2005.

28. Krantz BA, Dave N, Komatsubara KM, Marr BP and Carvajal RD: Uveal melanoma: Epidemiology, etiology, and treatment of primary disease. Clin Ophthalmol 11: 279-289, 2017.

29. Kaliki S, Shields CL and Shields JA: Uveal melanoma: Estimating prognosis. Indian J Ophthalmol 63: 93-102, 2015.

30. Singh M, Durairaj P and Yeung J: Uveal melanoma: A review of the literature. Oncol Ther 6: 87-104, 2018

31. Territo C, Shields CL, Shields JA, Augsburger JJ and Schroeder RP: Natural course of melanocytic tumors of the iris. Ophthalmology 95: 1251-1255, 1988.

32. Shields CL, Kaliki S, Hutchinson A, Nickerson S, Patel J, Kancherla S, Peshtani A, Nakhoda S, Kocher K, Kolbus E, et al: Iris nevus growth into melanoma: Analysis of 1611 consecutive eyes: The ABCDEF guide. Ophthalmology 120: 766-772, 2013.

33. Sumich P, Mitchell P and Wang JJ: Choroidal nevi in a white population: The blue mountains eye study. Arch Ophthalmol 116 645-650, 1998

34. Singh AD, Kalyani $P$ and Topham A: Estimating the risk of malignant transformation of a choroidal nevus. Ophthalmology 112 1784-1789, 2005.

35. Shields CL, Cater J, Shields JA, Singh AD, Santos MC and Carvalho C: Combination of clinical factors predictive of growth of small choroidal melanocytic tumors. Arch Ophthalmol 118 $360-364,2000$

36. Damato BE, Heimann H, Kalirai H and Coupland SE: Age, survival predictors, and metastatic death in patients with choroidal melanoma: Tentative evidence of a therapeutic effect on survival. JAMA Ophthalmol 132: 605-613, 2014.
37. Straatsma BR, Diener-West M, Caldwell R and Engstrom RE; Collaborative Ocular Melanoma Study Group: Mortality after deferral of treatment or no treatment for choroidal melanoma. Am J Ophthalmol 136: 47-54, 2003.

38. Jager MJ, Shields CL, Cebulla CM, Abdel-Rahman MH, Grossniklaus HE, Stern MH, Carvajal RD, Belfort RN, Jia R, Shields JA and Damato BE: Uveal melanoma. Nat Rev Dis Primers 6: 24, 2020

39. Singh AD, Rennie IG, Kivela T, Seregard S and Grossniklaus H: The Zimmerman-McLean-Foster hypothesis: 25 years later. Br J Ophthalmol 88: 962-967, 2004

40. No authors listed: The collaborative ocular melanoma study (COMS) randomized trial of pre-enucleation radiation of large choroidal melanoma II: Initial mortality findings. COMS report no. 10. Am J Ophthalmol 125: 779-796, 1998.

41. Collaborative Ocular Melanoma Study Group: The COMS randomized trial of iodine 125 brachytherapy for choroidal melanoma: V. Twelve-year mortality rates and prognostic factors: COMS report No. 28. Arch Ophthalmol 124: 1684-1693, 2006.

42. Rospond-Kubiak I and Damato B: The surgical approach to the management of anterior uveal melanomas. Eye (Lond) 28:741-747, 2014.

43. Shields JA, Shields CL, Shah P and Sivalingam V: Partial lamellar sclerouvectomy for ciliary body and choroidal tumors. Ophthalmology 98: 971-983, 1991.

44. Caminal JM, Mejia K, Masuet-Aumatell C, Arias L, Piulats JM, Gutierrez C, Pera J, Catala J, Rubio $M$ and Arruga J: Endoresection versus iodine-125 plaque brachytherapy for the treatment of choroidal melanoma. Am J Ophthalmol 156: 334-342.e1, 2013.

45. Biewald E, Lautner H, Gök M, Horstmann GA, Sauerwein W, Flühs D and Bornfeld N: Endoresection of large uveal melanomas: Clinical results in a consecutive series of 200 cases. Br J Ophthalmol 101: 204-208, 2017.

46. Süsskind D, Dürr C, Paulsen F, Kaulich T and Bartz-Schmidt KU: Endoresection with adjuvant ruthenium brachytherapy for selected uveal melanoma patients-the Tuebingen experience. Acta Ophthalmol 95: e727-e733, 2017.

47. Brewington BY, Shao YF, Davidorf FH and Cebulla CM: Brachytherapy for patients with uveal melanoma: Historical perspectives and future treatment directions. Clin Ophthalmol 12: 925-934, 2018.

48. Dogrusöz M, Jager MJ and Damato B: Uveal melanoma treatment and prognostication. Asia Pac J Ophthalmol (Phila) 6: 186-196, 2017.

49. Weis E, Salopek TG, McKinnon JG, Larocque MP, TempleOberle C, Cheng T, McWhae J, Sloboda R and Shea-Budgell M: Management of uveal melanoma: A consensus-based provincial clinical practice guideline. Curr Oncol 23: e57-e64, 2016.

50. Fallico M, Raciti G, Longo A, Reibaldi M, Bonfiglio V, Russo A, Caltabiano R, Gattuso G, Falzone L and Avitabile T: Current molecular and clinical insights into uveal melanoma (review). Int J Oncol 58: 10, 2021.

51. Chang MY and McCannel TA: Local treatment failure after globeconserving therapy for choroidal melanoma. Br J Ophthalmol 97: 804-811, 2013.

52. Grange JD, Duquesne N, Roubeyrol F, Branisteanu D, Sandon K, Fleury J, Gerard JP, Chauvel P, Pinzaru G, Jean-Louis B and Bievelez B: Double irradiation for macroscopic radioresistance or recurrence of melanomas of the posterior uvea: Clinical, ballistic, therapeutic and prognostic aspects. Series of 19 cases among 462 patients. J Fr Ophtalmol 22: 1054-1063, 1999 (In French).

53. Stålhammar G: Forty-year prognosis after plaque brachytherapy of uveal melanoma. Sci Rep 10: 11297, 2020.

54. Yupari R, Bena J, Wilkinson D, Suh J and Singh A: Small choroidal melanoma: Outcomes following apical height dose brachytherapy. Br J Ophthalmol 105: 1161-1165, 2021.

55. Detorakis ET, Engstrom RE, Wallace R and Straatsma BR: Iris and anterior chamber angle neovascularization after iodine 125 brachytherapy for uveal melanoma. Ophthalmology 112: 505-510, 2005.

56. Krema H, Somani S, Sahgal A, Xu W, Heydarian M, Payne D, McGowan H, Michaels H, Simpson ER and Laperriere N: Stereotactic radiotherapy for treatment of juxtapapillary choroidal melanoma: 3-year follow-up. Br J Ophthalmol 93: 1172-1176, 2009.

57. Fallico M, Chronopoulos A, Schutz JS and Reibaldi M: Treatment of radiation maculopathy and radiation-induced macular edema: A systematic review. Surv Ophthalmol 66: 441-460, 2021. 
58. Indaram M, Ali FS and Levin MH: In search of a treatment for radiation-induced optic neuropathy. Curr Treat Options Neurol 17: 325, 2015.

59. Phillips C, Pope K, Hornby C, Chesson B, Cramb J and Bressel M: Novel 3D conformal technique for treatment of choroidal melanoma with external beam photon radiotherapy. J Med Imaging Radiat Oncol 57: 230-236, 2013.

60. Verma V and Mehta MP: Clinical outcomes of proton radiotherapy for uveal melanoma. Clin Oncol (R Coll Radiol) 28 e17-e27, 2016.

61. Gragoudas ES, Li W, Lane AM, Munzenrider J and Egan KM: Risk factors for radiation maculopathy and papillopathy after intraocular irradiation. Ophthalmology 106: 1571-1578, 1999.

62. Gragoudas ES: Proton beam irradiation of uveal melanomas: The first 30 years. The weisenfeld lecture. Invest Ophthalmol Vis Sci 47: 4666-4673, 2006.

63. Papakostas TD, Lane AM, Morrison M, Gragoudas ES and Kim IK: Long-term outcomes after proton beam irradiation in patients with large choroidal melanomas. JAMA Ophthalmol 135 1191-1196, 2017.

64. Parker T, Rigney G, Kallos J, Stefko ST, Kano H, Niranjan A, Green AL, Aziz T, Rath P, Lunsford LD: Gamma knife radiosurgery for uveal melanomas and metastases: A systematic review and meta-analysis. Lancet Oncol 21: 1526-1536, 2020.

65. Meyer Schwickerath G and Vogel M: Treatment of malignant melanomas of the choroid by photocoagulation. Trans Ophthalmol Soc UK 97: 416-420, 1977.

66. Foulds WS and Damato BE: Low-energy long-exposure laser therapy in the management of choroidal melanoma. Graefes Arch Clin Exp Ophthalmol 224: 26-31, 1986.

67. Mashayekhi A, Shields CL, Rishi P, Atalay HT, Pellegrini M, McLaughlin JP, Patrick KA, Morton SJ, Remmer MH, Parendo A, et al: Primary transpupillary thermotherapy for choroidal melanoma in 391 cases: Importance of risk factors in tumor control. Ophthalmology 122: 600-609, 2015.

68. Chojniak MM, Chojniak R, Nishimoto IN, Allemann N and Erwenne CM: Primary transpupillary thermotherapy for small choroidal melanoma. Graefes Arch Clin Exp Ophthalmol 249: $1859-1865,2011$

69. Turkoglu EB, Pointdujour-Lim R, Mashayekhi A and Shields CL: Photodynamic therapy as primary treatment for small choroidal melanoma. Retina 39: 1319-1325, 2019.

70. Yordi S, Soto H, Bowen RC and Singh AD: Photodynamic therapy for choroidal melanoma: What is the response rate? Surv Ophthalmol 66: 552-559, 2021

71. Diener-West M, Reynolds SM, Agugliaro DJ, Caldwell R, Cumming K, Earle JD, Green DL, Hawkins BS, Hayman J, Jaiyesimi I, et al: Screening for metastasis from choroidal melanoma: the collaborative ocular melanoma study group report 23 . J Clin Oncol 22: 2438-2444, 2004

72. Kujala E, Mäkitie T and Kivelä T: Very long-term prognosis of patients with malignant uveal melanoma. Invest Ophthalmol Vis Sci 44: 4651-4659, 2003

73. Damato B, Eleuteri A, Taktak AF and Coupland SE: Estimating prognosis for survival after treatment of choroidal melanoma Prog Retin Eye Res 30: 285-295, 2011.

74. Rebegea L, Firescu D, Baciu G and Ciubara A: Psycho-oncology support. BRAIN 10: 77-88, 2019.

75. Pföhler C, Cree IA, Ugurel S, Kuwert C, Haass N, Neuber K, Hengge U, Corrie PG, Zutt M, Tilgen W and Reinhold U: Treosulfan and gemcitabine in metastatic uveal melanoma patients: Results of a multicenter feasibility study. Anticancer Drugs 14: 337-340, 2003

76. Săftescu S, Popovici D, Oprean C, Negru A, Croitoru A, Zemba M, Yasar I, Preda M and Negru S: Endurance of erythrocyte series in chemotherapy. Exp Ther Med 20: 214, 2020.

77. Nathan FE, Berd D, Sato T, Shield JA, Shields CL, De Potter P and Mastrangelo MJ: BOLD+interferon in the treatment of metastatic uveal melanoma: First report of active systemic therapy. J Exp Clin Cancer Res 16: 201-208, 1997.

78. Kirchberger MC, Moreira A, Erdmann M, Schuler G and Heinzerling L: Real world experience in low-dose ipilimumab in combination with PD-1 blockade in advanced melanoma patients. Oncotarget 9: 28903-28909, 2018.
79. Pelster MS, Gruschkus SK, Bassett R, Gombos DS, Shephard M, Posada L, Glover MS, Simien R, Diab A, Hwu P, Carter BW and Patel SP: Nivolumab and ipilimumab in metastatic uveal melanoma: Results from a single-arm phase II study. J Clin Oncol 39: 599-607, 2021

80. Buga A, Docea AO, Albu C, Malin RD, Branisteanu DE, Ianosi G, Ianosi SL, Iordache A and Calina D: Molecular and cellular stratagem of brain metastases associated with melanoma (review). Oncol Lett 17: 4170-4175, 2019.

81. Radu A, Bejenaru C, Ţolea I, Maranduca MA, Brănişteanu DC, Bejenaru LE, Petrariu FD, Stoleriu G and Brănişteanu DE: Immunohistochemical study of CD117 in various cutaneous melanocytic lesions. Exp Ther Med 21: 78, 2021.

82. Najjar YG, Navrazhina K, Ding F, Bhatia R, Tsai K, Abbate K, Durden B, Eroglu Z, Bhatia S, Park S, et al: Ipilimumab plus nivolumab for patients with metastatic uveal melanoma: A multicenter, retrospective study. J Immunother Cancer 8: e000331, 2020

83. Carvajal RD, Schwartz GK, Tezel T, Marr B, Francis JH and Nathan PD: Metastatic disease from uveal melanoma: Treatment options and future prospects. Br J Ophthalmol 101: 38-44, 2017.

84. Piperno-Neumann S, Kapiteijn E, Larkin JM, Carvajal RD, Luke JJ, Roozen HS, Zoubir M, Yang L, Choudhury S, Yerramilli-Rao $\mathrm{P}$, et al: Phase I dose-escalation study of the protein kinase $\mathrm{C}$ (PKC) inhibitor AEB071 in patients with metastatic uveal melanoma. J Clin Oncol 32 (Suppl 15): 9030, 2014.

85. Leyvraz S, Piperno-Neumann S, Suciu S, Baurain JF, Zdzienicki M, Testori A, Marshall E, Scheulen M, Jouary T, Negrier S, et al: Hepatic intra-arterial versus intravenous fotemustine in patients with liver metastases from uveal melanoma (EORTC 18021): A multicentric randomized trial. Ann Oncol 25: 742-746, 2014.

86. Mallone F, Sacchetti M, Lambiase A and Moramarco A: Molecular insights and emerging strategies for treatment of metastatic uveal melanoma. Cancers (Basel) 12: 2761, 2020.

87. Siegel R, Hauschild A, Kettelhack C, Kähler KC, Bembenek A and Schlag PM: Hepatic arterial Fotemustine chemotherapy in patients with liver metastases from cutaneous melanoma is as effective as in ocular melanoma. Eur J Surg Oncol 33: 627-632, 2007.

88. Gonsalves CF, Eschelman DJ, Thornburg B, Frangos A and Sato T: Uveal melanoma metastatic to the liver: Chemoembolization with 1,3-Bis-(2-chloroethyl)-1-nitrosourea. AJR Am J Roentgenol 205: 429-433, 2015.

89. Artzner C, Mossakowski O, Hefferman G, Grosse U, Hoffmann R, Forschner A, Eigentler T, Syha R and Grözinger G: Chemosaturation with percutaneous hepatic perfusion of melphalan for liver-dominant metastatic uveal melanoma: A single center experience. Cancer Imaging 19: 31, 2019.

90. Mariani P, Piperno-Neumann S, Servois V, Berry MG, Dorval T, Plancher C, Couturier J, Levy-Gabriel C, Lumbroso-Le Rouic L, Desjardins L and Salmon RJ: Surgical management of liver metastases from uveal melanoma: 16 years' experience at the Institut Curie. Eur J Surg Oncol 35: 1192-1197, 2009.

91. Bale R, Schullian P, Schmuth M, Widmann G, Jaschke W and Weinlich G: Stereotactic radiofrequency ablation for metastatic melanoma to the liver. Cardiovasc Intervent Radiol 39: 1128-1135, 2016.

92. Gonsalves CF, Eschelman DJ, Adamo RD, Anne PR, Orloff MM, Terai M, Hage AN, Yi M, Chervoneva I and Sato T: A prospective phase II trial of radioembolization for treatment of uveal melanoma hepatic metastasis. Radiology 293: 223-231, 2019.

93. Rodriguez-Vidal C, Fernandez-Diaz D, Fernandez-Marta B, Lago-Baameiro N, Pardo M, Silva P, Paniagua L, BlancoTeijeiro MJ, Piñeiro A and Bande M: Treatment of metastatic uveal melanoma: Systematic review. Cancers (Basel) 12: 2557, 2020.

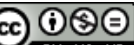

This work is licensed under a Creative Commons Attribution-NonCommercial-NoDerivatives 4.0 International (CC BY-NC-ND 4.0) License. 